\title{
Heart rate variability - clinical significance
}

\author{
DOMINIKA URBANIK ${ }^{A, E, F}$, MACIEJ PODGÓRSKIE, F, GRZEGORZ MAZUR E, F
}

Department of Internal Medicine, Occupational Diseases, Hypertension and Clinical Oncology, Wroclaw Medical University, Poland

A - Study Design, B - Data Collection, C - Statistical Analysis, D - Data Interpretation, E - Manuscript Preparation, F - Literature Search, G - Funds Collection

Summary Heart rate variability (HRV) is a statistical evaluation of ECG Holter analysis used for non-invasive assessment of autonomic nervous system activity. The autonomic nervous system plays a major role in human homeostasis. Autonomic dysfunction and altered HRV are observed in many life-threatening conditions, like myocardial infarction, multiple organ dysfunction syndrome, sepsis and severe brain injuries. Analysis of HRV uses two major techniques for assessing ECG intervals - time and frequency analysis. Additionally, there is also an alternative non-linear method of assessing HRV called fractal analysis. Clinical evaluation of HRV has been performed in medicine for more than three decades. Recent studies show that heart rate variability is a strong predictor of cardiovascular risk and mortality. It has also become common practice in everyday medicine, especially in family medicine, cardiology, neurology and psychiatry. There are some variables affecting HRV analysis: age, gender, physical activity and body mass index. Age and body mass index have negative correlation with HRV. Correlation of gender with HRV is not clearly specified in literature. Recent studies show that young males have increased HRV, and this diminishes faster during aging. Young women present decreased values of HRV, but these differences become indistinguishable after 50 . Physical activity may enhance HRV by increasing vagal tone and decreasing sympathetic activity. Key words: heart rate, autonomic dysfunction, cardiovascular risk.

Urbanik D, Podgórski M, Mazur G. Heart rate variability - clinical significance. Fam Med Prim Care Rev 2018; 20(1): 87-90, doi: https:// doi.org/10.5114/fmpcr.2018.73710.

\section{Definition of HRV}

Heart rate variability (HRV) is a statistical evaluation of ECG Holter analysis used for non-invasive assessment of autonomic nervous system activity. HRV determines consecutive NN (or RR) intervals of the sinus rhythm on time pre-defined ECG strips, ranging from a few minutes to 24 hours, and presents its results in the form of a mathematical table. The parameters used in HRV analysis proved to be non-invasive markers of the activity of the autonomic nervous system and have showed to have prognostic value in evaluation of cardiovascular risk [1]. Assessment of HRV requires accurate detection of sinus rhythm, and thus has some limitations, e.g. arrhythmias, premature atrial and ventricular beats, atrial fibrillation provide false results of the analysis and must be removed from the NN sequences. Furthermore, HRV parameters can be compared from different recordings but of the same time intervals [2].

The clinical relevance of heart rate variability has been published in many scientific reports; the first were noted in 1965 by Hon and Lee. They found that fetal distress was preceded by alterations of beat to beat intervals of the ECG analysis, even before any visible heart rate changes occurred [3]. Further research on combined HRV analysis proved to have a prognostic value in diabetic patients. Finally, in 1970-1980, many studies proved the clinical advantage of HRV as a strong and independent predictor of mortality after acute myocardial infarction. This correlation was first disclosed by Wolf et al. in 1978 [4].

\section{Methods of analysis}

Heart rate variability uses two major techniques for assessing ECG intervals - time and frequency analysis. Time domain parameters are used to evaluate beat to beat intervals, and frequency domain measures present a spectral analysis of heartbeat patterns [5].
Time analysis of 24-hour ECG recording uses the following parameters:

- $\quad \mathrm{mNN}$ - mean NN interval;

- $\quad$ SDNN - standard deviation of all normal NN intervals. There can be two variants of SDNN : SDANN and SDNN index. SDANN is the standard deviation of all 5-minute NN interval means, and the SDNN index is the mean of all the 5-minute standard deviations of $\mathrm{NN}$;

- $\quad r-M S S D$ and pNN50. The r-MSSD (root-mean-square successive difference) calculates the square root of the mean squared differences between consecutive NN intervals. The pNN50 estimates the percentage differences of successive NN intervals which are greater than 50 milliseconds.

SDNN is a measure of total heart rate variability, SDANN measures the long-term variation and SDNN index, while r-MSSD and pNN50 measure the short-term variation [6]. All time domain indices, except pNN50, have units of time in milliseconds.

Frequency analysis is based on power spectral density (PSD). The calculations require a computer algorithm, called the fast Fourier transform (FFT). PSD presents the distribution of power (variance) as a function of the frequency. The following frequency domain parameters are analyzed:

- $\quad \mathrm{HF}$ (high frequency) - from 0.15 to $0.4 \mathrm{~Hz}$, reflects parasympathetic activity and respiratory sinus arrhythmia, which correlates with r-MSSD and pNN50;

- LF (low frequency) - from 0.04 to $0.15 \mathrm{~Hz}$, reflects both sympathetic and parasympathetic activity [6]. LF is associated with the peripheral baroreceptor system and is considered as an indicator of sympathetic activation [7];

- $\quad \operatorname{VLF}$ (very low frequency) - from 0.003 to $0.04 \mathrm{~Hz}$, and ULF (ultralow frequency) - below $0.003 \mathrm{~Hz}$. VLF and ULF reflect long-term variability and correlate with SDANN. VLF is modulated by neurohormonal activity, including the renin-angiotensin-aldosterone system and by thermoregulation [8]; 
- $\quad$ TP (total power) - the variance of all NN intervals, which combines every component and reflects total rate variability and correlates with SDNN;

- $\quad \mathrm{LF} / \mathrm{HF}$ - ratio LF/HF, which presents the proportion between the sympathetic and parasympathetic nervous system.

Frequency domain parameters are measured in absolute values of power $\mathrm{ms}^{2}$. Measurements of HF and LF can be calculated into the relative indices, normalized units (n.u.). This is the ratio of each power component to the difference between total power and VLF.

Time and frequency domain variables use conventional linear algorithms. There is also an alternative non-linear method of assessing HRV called fractal analysis. This method includes the Power Law Exponent, Approximate Entropy and Detrended Fluctuation Analysis [9]. Various research proves the prognostic role of fractal parameters in determining cardiovascular risk and cardiac mortality [10]. Non-linear analysis also describes the interactions between various complex systems, including the hemodynamic, electrophysiological, humoral, autonomic and central nervous systems.

\section{Prognostic value of HRV}

The autonomic nervous system plays a major role in human homeostasis [11]. Autonomic dysfunction is observed in many life-threatening conditions, like myocardial infarction, multiple organ dysfunction syndrome [12], sepsis [13] and severe brain injuries [14]. Based on many clinical trials, heart rate variability proved to be a good tool to evaluate autonomic dysfunction and a strong prognostic marker of mortality and severe arrhythmias diagnosed after myocardial infarction. There was a proposal of threshold values for standard time parameters: SDNN $<50$ $\mathrm{ms}$ indicates a very poor prognosis, and SDNN $<100 \mathrm{~ms}$ indicates a moderate poor prognosis [6]. There is also evidence that fractal parameters are good markers of post-infarction mortality. One multicenter prospective study (697 patients after AMI) indicated that fractal parameters are considered to be even more significant markers than time domain [15]. Recent treatment options to AMI, like percutaneous interventions, limited the wide usage of $\mathrm{HRV}$ after early reperfusion. A retrospective cohort study, based on 326 patients undergoing percutaneous coronary intervention, revealed a low percentage of cases that decreased HRV after myocardial infarction [16]. Assessment of the autonomic nervous system has also been found to be significant in estimating cardiovascular risk in patients with heart failure (HF). Heart rate variability, baroreflex sensitivity, left ventricular ejection fraction and ventricular arrhythmias proved to have prognostic values in cardiovascular mortality in HF [17]. La Rovere et al. examined linear and non-linear analysis of HRV in 388 patient with heart failure and found that autonomic indexes have an independent predictive value on the long-term outcome in HF patients [18], however, there is an exception. Patients undergoing Coronary Artery Bypass Grafting (CABG) have reduced HRV up to six months after the procedure. The etiology is complex and indicates the combined effects of surgical manipulation on the heart, anesthesia, cardioplegia and extracorporeal circulation. These patients have decreased HRV, and this does not correlate with overall mortality [19].

Frequency domain analysis may also be used to predict the pathophysiology of cardiac arrest in HF: pump failure vs sudden death in patients with preserved sinus rhythm [20].

Autonomic dysregulation is also associated with essential hypertension. The study conducted by Mussalo et al. showed that in time and frequency domain analysis, there is a positive correlation between the severity of hypertension and the severity of impairment of cardiac autonomic control [21].

$\mathrm{HRV}$ is also evaluated in neurology and psychiatry. The degree of HRV reduction can reflect the severity of brain damage.
It has been observed that an increase of intracranial pressure results in rapid HRV decrease [22]. A strong negative correlation between HRV and the degree of central nervous system injury was first demonstrated in the 1990s in pediatric populations. HRV analysis may be helpful in predicting [23] and confirming brain death [24]. At the onset of the 21st century, autonomic dysregulation was found to be a significant marker in stroke patients. Studies revealed that the nonlinear parameters of HRV are reliable when assessing the outcome of cerebral ischemia and can predict Stroke-In-Evolution (SIE) in acute ischemic patients. Chen et al. assessed HRV on a non-linear analysis of 90 patients with non-atrial fibrillation acute ischemic stroke. They found that fractal analysis HRV multiscale entropy (MSE) was significantly decreased in patient suffering from SIE and presented MSE as a potential post-stroke predictor of SIE [25]. Epilepsy is another neurological disorder with sympathovagal imbalance [26] and is often accompanied by lower HF, SDNN and RMSSD values when compared to controls [27]. This implicates an association with fatal arrhythmias and sudden unexpected death in epilepsy (SUDEP), which is partly the result of parasympathetic predominance [28]. Reduced HRV can also be observed in many studies regarding psychiatric disorders, depression, schizophrenia, anxiety and substance addiction. The greatest effect of reduced HRV is observed in individuals with psychotic disorders [29].

\section{Variables affecting HRV analysis}

Clinical evaluation of HRV has been performed in medicine for more than three decades. Although it has proven to be a good marker of autonomic nervous system activity and cardiovascular risk, there are still no complete guidelines on determining the norms of its parameters. Commonly used documents were published by NASPE and ESC in 1996 [6] but have some major limitations. They do not include variabilities, like the influence of age and gender. Recent studies show that age, gender, physical activity and body mass index affect heart rate variability.

The influence of age is quite visible in the time domain parameters of $\mathrm{HRV}$ analysis. The most sensitive changes affect the pNN50 index, which starts to drop even in 20-30-year-old subjects and consequently decreases, reaching a 76\% drop in the baseline value (estimated as the mean values of 20 -year-old subjects) by the end of sixth decade. For comparison, rMSSD by the age of 60 reaches approx. 50\%. HRV determined by SDNN and SDANN decreases at a slower rate, mostly between the second and the third decade [30]. However, there are also some studies that show the limitations of time domain indexes. Jokinen et al. conducted a follow-up study which included a fractal analysis. In the 32 months of follow up Holter recordings, they found no significant correlation between traditional time and frequency domain measures and heart rate variability. Furthermore, the fractal analysis turned out to be more sensitive than traditional methods in evaluating age-related HRV alterations [31].

The data in literature concerning gender is inconsistent. Some studies show that females are considered to have higher HRV parameters, due to parasympathetic system predominance [32]. This approach would explain the burden of the high cardiovascular risk in men. Others conclude that there are no major differences after a certain age. The HRV spread between sexes gradually decrease at an age of $>30$ years to finally disappear at an age $>50$ years [30,33]. Young females (10-29 years) have significantly lower HRV parameters than the same age-matched males, but the rate of decrease with aging is much faster in males [30].

Physical activity and body mass index can contribute to healthy longevity via parasympathetic activation [34]. Exercise training may enhance HRV by increasing vagal tone and decreasing sympathetic activity. This also affects the reduction of heart 
rate, which leads to oxygen consumption decline [35]; hence, the greatest benefit from exercise therapy was demonstrated in patients with myocardial infarction [36], chronic heart failure and in patients after revascularization. Body mass index has an inverse correlation between HRV and body weight [37-39].

\section{The role of HRV in family medicine}

Stratification of cardiovascular risk plays a major role in family medicine, especially in the daily care of diabetic and cardiac patients [11]. Heart rate variability, as a strong predictor of cardiovascular risk and mortality, allows the general practitioner to obtain an introduction to optimal medical treatment. Patients after myocardial infarction and those with heart failure or diabetes appear to have double the risk of mortality when autonomic dysfunction is found [40]. HRV is a better tool for the general practitioner to seek out such patients and introduce proper prophylaxis or guide them towards specialist care.
There are many useful tools to evaluate cardiovascular risk in the daily practice of family medicine, e.g. score charts, risk calculators, surveys. They allow one to increase compliance with patients undergoing cardiovascular treatment. HRV can be used as an additional method to graphically present the current risk to patients. The more narrowed the HRV graph, the greater the cardiovascular risk present [6].

\section{Conclusions}

Heart rate variability proved to be a strong predictor of cardiovascular risk and mortality. It is also a great tool to estimate autonomic nervous system activity. It is commonly practiced in everyday medicine, especially in cardiology and neurology. However, there are many other diseases affected by autonomic dysregulations, where HRV is still under investigations, such as: sleep apnea, chronic kidney disease, irritable bowel syndrome, muscular dystrophy, Guillain-Barre syndrome and Parkinson disease.

Source of funding: This work was funded by the authors' own resources.

Conflict of interest: The authors declare no conflict of interests.

\section{References}

1. Billman GE. Heart rate variability - a historical perspective. Front Physiol 2011; 2(86): 1-13.

2. Bilchick KC, Berger RD. Heart rate variability. J Cardiovasc Electrophysiol 2006; 17(6): 691-694.

3. Hon EH, Lee ST. Electronic evaluations of fetal heart rate patterns preceding fetal death, further observations. Am J Obstet Gynecol 1965; 87: 814-826.

4. Wolf MM, Varigos GA, Hunt D, et al. Sinus arrhythmia in acute myocardial infarction. Med J Aust 1978; 2(2): 52-53.

5. Kleiger RE, Stein PK, Bigger JT. Heart rate variability: measurement and clinical utility. Ann Noninvasive Electrocardiol 2005; 10(1): 88-101.

6. Malik M, Bigger T, Camm AJ, et al. Heart rate variability: standards of measurement, physiological interpretation and clinical use. Task Force of the European Society of Cardiology and the North American Society of Pacing and Electrophysiology. Circulation 1996; 93(5): 1043-1065.

7. Malik M, Camm AJ. Components of heart rate variability - what they really mean and what we really measure. Am J Cardiol 1993; 72(11): 821-822.

8. Taylor JA, Carr DL, Myers CW, et al. Mechanisms underlying very-low-frequency RR-interval oscillations in humans. Circulation 1998; 98(6): 547-555.

9. Buccelletti F, Bocci MG, Gilardi E, et al. Linear and nonlinear heart rate variability indexes in clinical practice. Comput Math Methods Med 2012; doi: http://dx.doi.org/10.1155/2012/219080.

10. Mäkikallio TH, Tapanainen JM, Tulppo MP, et al. Clinical applicability of heart rate variability analysis by methods based on nonlinear dynamics. Card Electrophysiol Rev 2002; 6(3): 250-255.

11. Gang Y, Malik M. Heart rate variability analysis in general medicine. Indian Pacing Electrophysiol J 2003; 3(1): 34-40.

12. Schmidt H, Müller-Werdan U, Hoffmann T, et al. Autonomic dysfunction predicts mortality in patients with multiple organ dysfunction syndrome of different age groups. Crit Care Med 2005; 33(9): 1994-2002.

13. Korach M, Sharshar T, Jarrin I, et al. Cardiac variability in critically ill adults: influence of sepsis. Crit Care Med 2001; 29(7): 1380-1385.

14. Winchell RJ, Hoyt DB. Analysis of heart-rate variability: a noninvasive predictor of death and poor outcome in patients with severe head injury. J Trauma 1997; 43(6): 927-933.

15. Tapanainen JM, Thomsen PEB, Køber L, et al. Fractal analysis of heart rate variability and mortality after an acute myocardial infarction. Am J Cardiol 2002; 90(4): 347-352.

16. Compostella L, Lakusic N, Compostella C, et al. Does heart rate variability correlate with long-term prognosis in myocardial infarction patients treated by early revascularization? World J Cardiol 2017; 9(1): 27-38.

17. La Rovere MT, Pinna GD, Hohnloser SH, et al. Baroreflex sensitivity and heart rate variability in the identification of patients at risk for life-threatening arrythmias. Circulation 2001; 103(16): 2072-2077.

18. La Rovere MT, Pinna GD, Maestri R, et al. Autonomic markers and cardiovascular and arrhythmic events in heart failure patients: still a place in prognostication? Data from the GISSI-HF trial. Eur J Heart Fail 2012; 14(12): 1410-1419.

19. Lakusic N, Mahovic D, Kruzliak P, et al. Changes in heart rate variability after coronary artery bypass grafting and clinical importance of these findings. Biomed Res Int 2015; doi: http://dx.doi.org/10.1155/2015/680515.

20. Guzzetti S, La Rovere MT, Pinna GD, et al. Different spectral components of $24 \mathrm{~h}$ heart rate variability are related to different modes of death in chronic heart failure. Eur Heart J 2005; 26(4): 357-362.

21. Mussalo H, Vanninen E, Ikäheimo R, et al. Heart rate variability and its determinants in patients with severe or mild essential hypertension. Clin Physiol 2001; 21(5): 594-604.

22. Lowensohn RI, Weiss M, Hon EH. Heart-rate variability in brain-damaged adults. Lancet 1977; 1(8012): 626-628.

23. Rapenne $T$, Moreau $D$, Lenfant $F$, et al. Could heart rate variability predict outcome in patients with severe head injury? A pilot study. J Neurosurg Anesthesiol 2001; 13(3): 260-268.

24. Conci F, Di Rienzo M, Castiglioni P. Blood pressure and heart rate variability and baroreflex sensitivity before and after brain death. J Neurol Neurosurg Psychiatry 2001; 71(5): 621-631.

25. Chen C-H, Huang P-W, Tang S-C, et al. Complexity of heart rate variability can predict stroke-in-evolution in acute ischemic stroke patients. Sci Rep 2015; 5(17552): 1-5, doi: 10.1038/srep17552. 
26. Jansen K, Lagae L. Cardiac changes in epilepsy. Seizure 2010; 19(8): 455-460.

27. Lotufo PA, Valiengo L, Benseñor IM, et al. A systematic review and meta-analysis of heart rate variability in epilepsy and antiepileptic drugs. Epilepsia $2012 ; 53(2): 272-282$.

28. DeGiorgio CM, Miller P, Meymandi S, et al. RMSSD, a measure of heart rate variability, is associated with risk factors for SUDEP: the SUDEP-7 inventory. Epilepsy Behav 2010; 19(1): 78-81.

29. Alvares GA, Quintana DS, Hickie IB, et al. Autonomic nervous system dysfunction in psychiatric disorders and the impact of psychotropic medications: a systematic review and meta-analysis. J Psychiatry Neurosci 2016; 41(2): 89-104.

30. Umetani K, Singer DH, McCraty R, et al. Twenty-four hour time domain heart rate variability and heart rate: relations to age and gender over nine decades. J Am Coll Cardiol 1998; 31(3): 593-601.

31. Jokinen V, Syvänne M, Mäkikallio TH, et al. Temporal age-related changes in spectral, fractal and complexity characteristics of heart rate variability. Clin Physiol 2001; 21(3): 273-281.

32. Ryan SM, Goldberger AL, Pincus SM, et al. Gender- and age-related differences in heart rate dynamics: are women more complex than men? J Am Coll Cardiol 1994; 24(7): 1700-1707.

33. Stein PK, Kleiger RE, Rottman JN. Differing effects of age on heart rate variability in men and women. Am J Cardiol 1997; 80(3): 302-305.

34. Zulfiqar U, Jurivich DA, Gao W, et al. Relation of high heart rate variability to healthy longevity. Am J Cardiol 2010; 105(8): 1181-1185.

35. Buch AN, Coote JH, Townend JN. Mortality, cardiac vagal control and physical training - what's the link? Exp Physiol 2002; 87(4): 423-435.

36. Sandercock GRH, Grocott-Mason R, Brodie DA. Changes in short-term measures of heart rate variability after eight weeks of cardiac rehabilitation. Clin Auton Res 2007; 17(1): 39-45.

37. Karason K, Mølgaard H, Wikstrand J, et al. Heart rate variability in obesity and the effect of weight loss. Am J Cardiol 1999; 83(8): $1242-1247$.

38. Koenig J, Jarczok MN, Warth $\mathrm{M}$, et al. Body mass index is related to autonomic nervous system activity as measured by heart rate variability - a replication using short term measurements. J Nutr Health Aging 2014; 18(3): 300-302.

39. Molfino A, Fiorentini A, Tubani $L$, et al. Body mass index is related to autonomic nervous system activity as measured by heart rate variability. Eur J Clin Nutr 2009; 63(10): 1263-1265.

40. Gerritsen J, Dekker JM, TenVoorde BJ, et al. Impaired autonomic function is associated with increased mortality, especially in subjects with diabetes, hypertension, or a history of cardiovascular disease: the Hoorn Study. Diabetes Care 2001; 24(10): 1793-1798.

Tables: 0

Figures: 0

References: 40

Received: 05.06.2017

Reviewed: 18.06 .2017

Accepted: 13.07.2017

Address for correspondence:

Dominika Urbanik, MD

Klinika Chorób Wewnętrznych, Zawodowych, Nadciśnienia Tętniczego i Onkologii Klinicznej

Uniwersytecki Szpital Kliniczny im. Jana Mikulicza-Radeckiego

ul. Borowska 213

50-556 Wrocław

Poland

Tel.: +48 $71736-40-00$

E-mail: dominika.urbanik@gmail.com 